\title{
THE IMPACT OF DEVELOPED POLYNOMIAL ON ACCURACY OF SETTING DOWN A POSITION'S COORDINATES BASED ON MEASUREMENTS OF TWO BEARINGS
}

\begin{abstract}
An attempt to determine the impact of developing polynomial on the accuracy of setting down a ship's position coordinates based on measurements of two bearings has been ventured in this paper. A navigation structure consisting of two aids has been analysed. A ship maneuvering within a given area was setting down her position in respect to them. As a result of this, numeral accuracy indexes were calculated. They gave principles for conclusions regarding the impact of the distance between the aids of navigation on the accuracy of setting down the position's coordinates.
\end{abstract}

\section{Keywords:}

accuracy, navigation, positioning, terrestrial.

\section{INTRODUCTION}

Identification of geographical position is a fundamental task of a navigator operating a ship at sea [Kołaczyński, 2013]. In coastal navigation, the navigator mostly does carry out this task by terrestrial methods, based on beacons available on the coast which geographical coordinates are known. Thus, an accuracy of the ship position coordinates' identification in the coastal zone depends on available navigational signs making the so-called navigational measurement structure [Naus et al., 2016; Wiśniewski, 1999, 2004]. 
A method of selecting two beacons regarding optimal accuracy in identifying position by the watercraft proceeding along a minesweeping path axis is elaborated in this paper.

\section{METHOD OF THE RESEARCH}

To determine - based on results of two bearings to the beacons - position of the watercraft, it is necessary to recognize the navigational signs and select the proper beacons for identification of the position.

This paper is a follow-up to the elaboration [Narloch, 2014] in which optimal distance between the beacons in a two-sign structure was determined, to obtain the highest accuracy of the positions under identification by the watercraft held by minesweeping (proceeding along the minesweeping path axis).

A graphical interpretation of the navigational situation under consideration is presented in Figure 1.

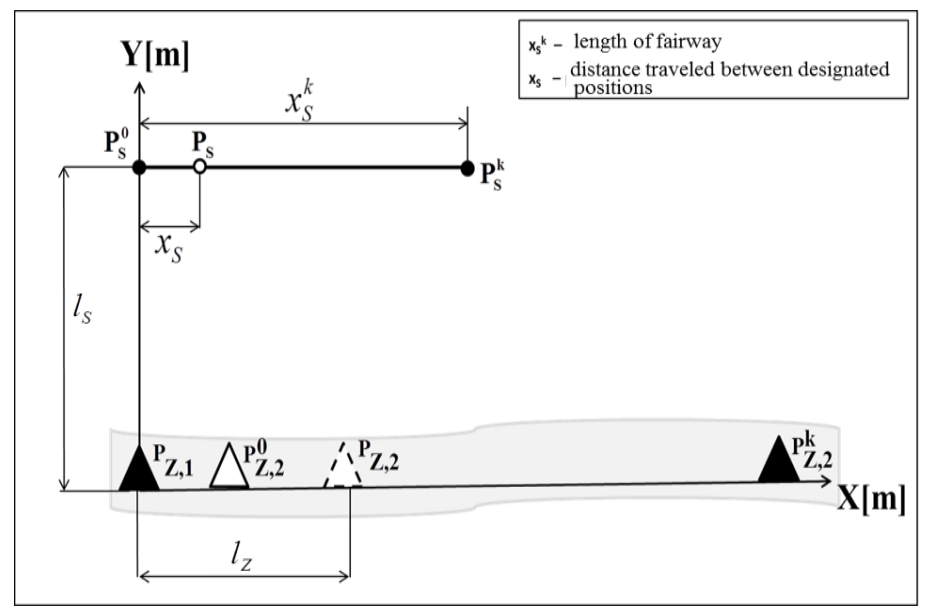

Fig. 1. Graphical interpretation of navigational situation

It is possible to formulate the following dependencies based on Figure 1:

$$
\mathbf{P}_{\mathbf{S}}^{\mathbf{0}}=\left(x_{S}^{0}, y_{S}^{0}\right)=(0,0) ;
$$




$$
\begin{gathered}
\mathbf{P}_{\mathbf{S}}=\left(x_{S}, y_{S}\right) ; \\
\mathbf{P}_{\mathbf{S}}^{\mathbf{k}}=\left(x_{S}^{k}, y_{S}^{k}\right) ; \\
\mathbf{P}_{\mathbf{Z}, \mathbf{1}}=\left(x_{Z, 1}, y_{Z, 1}\right)=(0,0) ; \\
\mathbf{P}_{\mathbf{Z , 2}}^{\mathbf{0}}=\left(x_{Z, 2}^{0}, y_{Z, 2}^{0}\right)=\left(x_{Z, 2}^{0}, 0\right) ; \\
\mathbf{P}_{\mathbf{Z , 2}}=\left(x_{Z, 2}, y_{Z, 2}\right)=\left(x_{Z, 2}, 0\right) ; \\
\mathbf{P}_{\mathbf{Z , 2}}^{\mathbf{k}}=\left(x_{Z, 2}^{k}, y_{Z, 2}^{k}\right)=\left(x_{Z, 2}^{k}, 0\right),
\end{gathered}
$$

where:

$\mathbf{P}_{\mathrm{S}}^{\mathbf{0}} \quad$ - starting position of the watercraft,

$\left(x_{S}^{0}, y_{S}^{0}\right)$ - coordinates of the watercraft starting position,

$\mathbf{P}_{\mathbf{S}} \quad$ - the current position of the watercraft,

$\left(x_{S}, y_{S}\right)$ - coordinates of the watercraft current position,

$\mathbf{P}_{\mathrm{S}}^{\mathbf{k}} \quad$ - the end position of the watercraft,

$\left(x_{S}^{k}, y_{S}^{k}\right)$ - coordinates of the watercraft end position,

$\mathbf{P}_{\mathrm{Z}, 1} \quad$ - the position of the beacon $Z, 1$,

$\left(x_{Z, 1}, y_{Z, 1}\right)$ - coordinates of the beacon $Z, 1$ position,

$\mathbf{P}_{\mathbf{Z}, 2}^{\mathbf{0}} \quad$ - starting position of the beacon $Z, 2$,

$\left(x_{Z, 2}^{0}, y_{Z, 2}^{0}\right)$ - coordinates of the beacon $Z, 2$ starting position,

$\mathbf{P}_{\mathbf{Z , 2}} \quad$ - the current position of the beacon $Z, 2$,

$\left(x_{Z, 2}, y_{Z, 2}\right)$ - coordinates of the beacon $Z, 2$ current position,

$\mathbf{P}_{\mathrm{Z}, 2}^{\mathbf{k}} \quad-$ the end position of the beacon $Z, 2$,

$\left(x_{Z, 2}^{k}, y_{Z, 2}^{k}\right)$ - coordinates of the beacon $Z, 2$ end position,

$l_{Z} \quad$ - the distance between the beacons $Z, 1$ and $Z, 2$ (length of the baseline, being a straight line connecting the beacons in the two-sign structure),

$l_{S} \quad$ - the distance between the fairway and the baseline, equal to the distance between the watercraft current position and the baseline. 
In order to determine optimal coordinates of the $Z, 2$ beacon position (i.e. to determine optimal distance between the beacons $Z, 1$ and $Z, 2$ ), the surface area was calculated below decomposition of mean error of the position under observation. It was determined based on measurements of two bearings to two beacons for every position of the watercraft, on the given distance of her proceeding along the minesweeping path axis. For this purpose, the following dependence was formulated [Czaplewski 1998, 1999, 2004; Kołaczyński, 1978]:

$$
P_{M_{2 N R}}=\int_{x_{S}^{0}}^{x_{S}^{k}} M_{2 N R} d x_{S}
$$

where

$P_{M_{2 N R}}$ - the surface area below decomposition of function $M_{2 N R}$.

In the final effect, according to formulas (9)-(17) described in the elaboration [Narloch, 2014] the following expression was obtained:

$$
P_{M_{2 N R}}=\int_{x_{S}^{0}}^{x_{S}^{k}} \frac{\sqrt{\left\{\left[x_{S}^{2}+\left(x_{S}-l_{Z}\right)^{2}+2 l_{S}^{2}\right]\left(x_{S}^{2}+l_{S}^{2}\right)\left[\left(l_{Z}-x_{S}\right)^{2}+l_{S}^{2}\right]\right\}}}{l_{Z} l_{S}} d x_{S} .
$$

Due to the fact that the above expression has no solution in a form of elementary function, the integrand was decomposed into the functional series, continuously convergent within the integral range $\left\langle\begin{array}{ll}x_{S}{ }^{0} & x_{S}{ }^{k}\end{array}\right\rangle$.

Accepting the below indication of the integrand [Gołąb, 1948]:

$$
f\left(x_{S}+h, l_{S}+k, l_{Z}+l\right)=\frac{\sqrt{\left\{\left[x_{S}^{2}+\left(x_{S}-l_{Z}\right)^{2}+2 l_{S}^{2}\right]\left(x_{S}^{2}+l_{S}^{2}\right)\left[\left(l_{Z}-x_{S}\right)^{2}+l_{S}^{2}\right]\right\}}}{l_{Z} l_{S}}
$$

The integrand was decomposed into the Taylor series, in this particular case - into the Maclaurin series, after the $x_{S}$ variable, in accordance with the dependence:

$$
f\left(x_{S}+h, l_{S}+k, l_{Z}+l\right)=f\left(x_{S}, l_{S}, l_{Z}\right)+\frac{1}{1 !}\left(\frac{\partial}{\partial x_{S}} h+\frac{\partial}{\partial l_{S}} k+\frac{\partial}{\partial l_{Z}} l\right) f\left(x_{S}, l_{S}, l_{Z}\right),
$$




$$
\begin{aligned}
& +\frac{1}{2 !}\left(\frac{\partial}{\partial x_{S}} h+\frac{\partial}{\partial l_{S}} k+\frac{\partial}{\partial l_{Z}} l\right)^{2} f\left(x_{S}, l_{S}, l_{Z}\right)+\frac{1}{3 !}\left(\frac{\partial}{\partial x_{S}} h+\frac{\partial}{\partial l_{S}} k+\frac{\partial}{\partial l_{Z}} l\right)^{3} f\left(x_{S}, l_{S}, l_{Z}\right),(11) \\
& +\frac{1}{4 !}\left(\frac{\partial}{\partial x_{S}} h+\frac{\partial}{\partial l_{S}} k+\frac{\partial}{\partial l_{Z}} l\right)^{4} f\left(x_{S}, l_{S}, l_{Z}\right)+\ldots+\frac{1}{n !}\left(\frac{\partial}{\partial x_{S}} h+\frac{\partial}{\partial l_{S}} k+\frac{\partial}{\partial l_{Z}} l\right)^{n} f\left(x_{S}, l_{S}, l_{Z}\right)+R_{n},
\end{aligned}
$$

where:

$$
R_{n}=\frac{1}{(n+1 !)}\left(\frac{\partial}{\partial x_{S}} h+\frac{\partial}{\partial l_{S}} k+\frac{\partial}{\partial l_{Z}} l\right)^{n+1} f\left(x_{S}+\theta_{1} h, l_{S}+\theta_{2} k, l_{Z}+\theta_{3} l\right)
$$

while:

$$
0<\theta_{1}<1,0<\theta_{2}<1,0<\theta_{3}<1
$$

In this paper, the author sought to answer a question - to which $n$ rank the integrand described with the dependence (10) should have been developed into a polynomial which value, for the known values $\left(x_{S}, l_{S}, l_{Z}\right)$, would square with the integrand value before the development into the given polynomial (of the initial integrand).

In the first part of this paper, in order to obtain the optimal polynomial developed into the demanded $n$ rank of the development, values of the absolute error and relative error were calculated with a use of the dependencies (14) and (15):

$$
\Delta f=\left|f\left(x_{S}+h, l_{S}+k, l_{Z}+l\right)-f\left(x_{S}+h, l_{S}+k, l_{Z}+l\right)_{\text {polynomial }}\right|,
$$

where:

$\Delta f$

- absolute error of the integrand developed into the polynomial to $n$ rank,

$f\left(x_{S}+h, l_{S}+k, l_{Z}+l\right) \quad$ - the integrand value (initial integrand),

$f\left(x_{S}+h, l_{S}+k, l_{Z}+l\right)_{\text {polynomial }}$ - the value of the integrand developed into the polynomial to $n$ rank.

$$
\delta=\frac{\Delta f}{f\left(x_{S}+h, l_{S}+k, l_{Z}+l\right)} \cdot 100 \%
$$


where:

$\delta$ - the relative error of the integrand developed into the polynomial to $n$ rank.

A polynomial for which values of the absolute error and relative error are minimal is the demanded polynomial fulfilling the assumed criteria.

In the second part of this paper, after determining the optimal polynomial, the value $l_{Z}$ - for which the function $P_{M_{2 N R}}$ reaches its minimum - was calculated (this is the assumed optimization criterion). The value $l_{Z}$ determined in this way consequently allowed for the determination of the $Z, 2$ beacon position (i.e. its coordinates) [Kopacz et al., 2007; Naus, 2014; Naus, Narloch, 2014]. The process of determining the above-said value $l_{Z}$ was carried out in identical way as in [Narloch, 2014], for the integrand being developed into the polynomials for particular $\mathrm{n}$ rank of the development. The obtained results permitted to make an analysis of accuracy indexes and conclusions.

\section{RESULTS OF TESTS}

The following values were accepted to control calculations during the development of the integrand into the polynomial:

- the length of the minesweeping path axis, the value $x_{S}^{k}$, is $15000 \mathrm{~m}$,

- the distance between the minesweeping path axis and the baseline $l_{S}$ is $18520 \mathrm{~m}$,

- the distance between the beacons $l_{Z}$ is $24055.1 \mathrm{~m}$.

Next, according to the theoretical assumptions and the dependence (11), integrand of the expression (10) was developed into the Taylor series, and values of the absolute errors and relative errors for particular $n$ ranks of the development were calculated. Table number 1 contains the calculated values of the absolute errors and relative errors for particular $\mathrm{n}$ rank development of the integrand into the polynomial.

A graphical interpretation of the integrand before its development into the polynomial is presented in Figure 2. 
Tab. 1. Values of absolute errors and relative errors for particular $\mathrm{n}$ rank development into integrand polynomial

\begin{tabular}{|c|c|c|}
\hline \multirow{3}{*}{$\begin{array}{l}\text { Value of } \boldsymbol{n} \text { rank developed into polynomial } \\
\text { after variable } x_{S}\end{array}$} & \multicolumn{2}{|c|}{$\begin{array}{c}\text { Integrand developed into polynomial } \\
\text { to } n \text { rank }\end{array}$} \\
\hline & Absolute error & Relative error \\
\hline & {$[\mathrm{m}]$} & {$[\%]$} \\
\hline$n=1$ & 20247.9 & 58.26 \\
\hline$n=2$ & 7683.0 & 22.11 \\
\hline$n=3$ & 2717.7 & 7.82 \\
\hline$n=4$ & 1089.8 & 3.14 \\
\hline$n=5$ & 332.6 & 0.96 \\
\hline$n=6$ & 355.8 & 1.02 \\
\hline$n=7$ & 136.4 & 0.39 \\
\hline$n=8$ & 183.9 & 0.53 \\
\hline$n=9$ & 44.0 & 0.13 \\
\hline$n=10$ & 90.4 & 0.26 \\
\hline$n=11$ & 13.9 & 0.04 \\
\hline$n=12$ & 43.3 & 0.12 \\
\hline$n=13$ & 6.0 & 0.02 \\
\hline$n=14$ & 21.9 & 0.06 \\
\hline
\end{tabular}

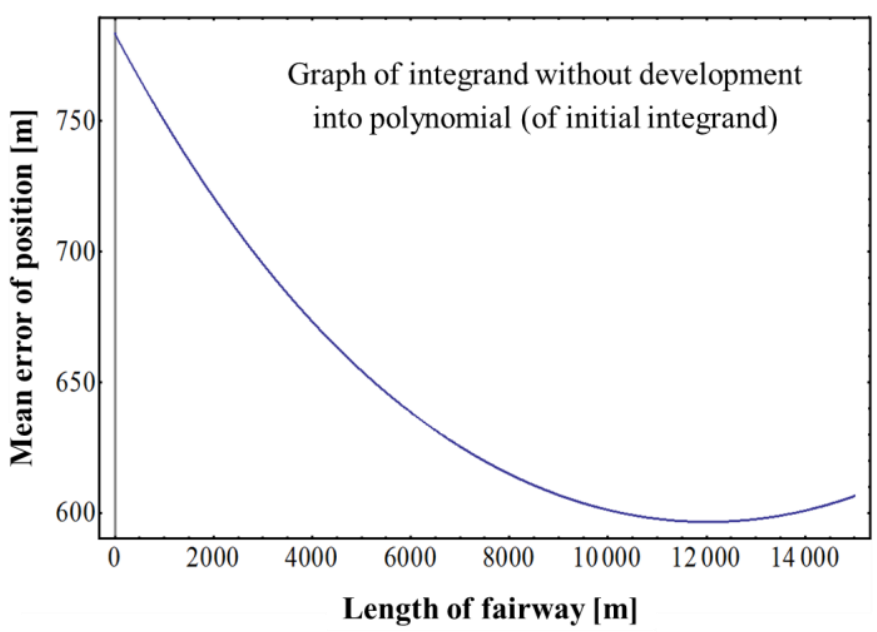

Fig. 2. Graphical interpretation of integrand without development into polynomial

In case of development of the integrand into the polynomial to $n=3$ rank, one would obtain the following differences in progress of the initial integrand in 
respect to its shape before development into the said polynomial — illustrated in Figure 3.

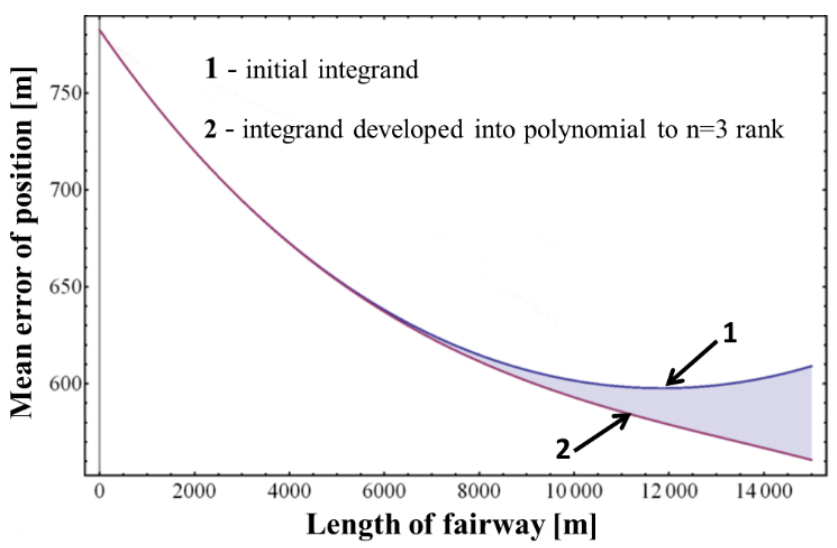

Fig. 3. Graphical interpretation of integrand without development into polynomial and of integrand developed into polynomial to $n=3$ rank

Graphical interpretation of decomposition of the absolute error and relative error of the integrand developed into the polynomial to $n=3$ rank after the variable $x_{S}$ is presented in Figures 4 and 5.

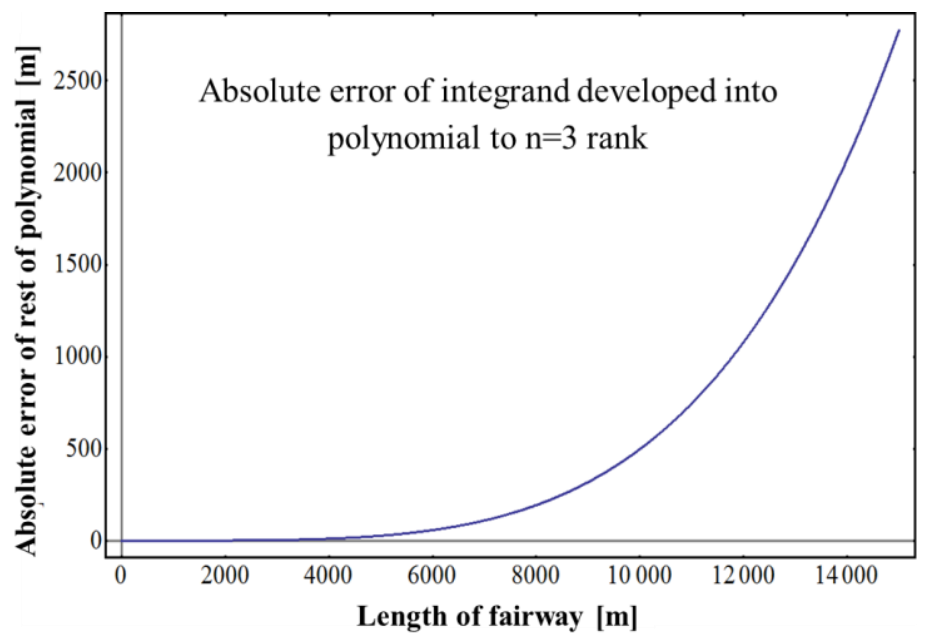

Fig. 4. Absolute error of integrand developed into polynomial to $n=3$ rank 


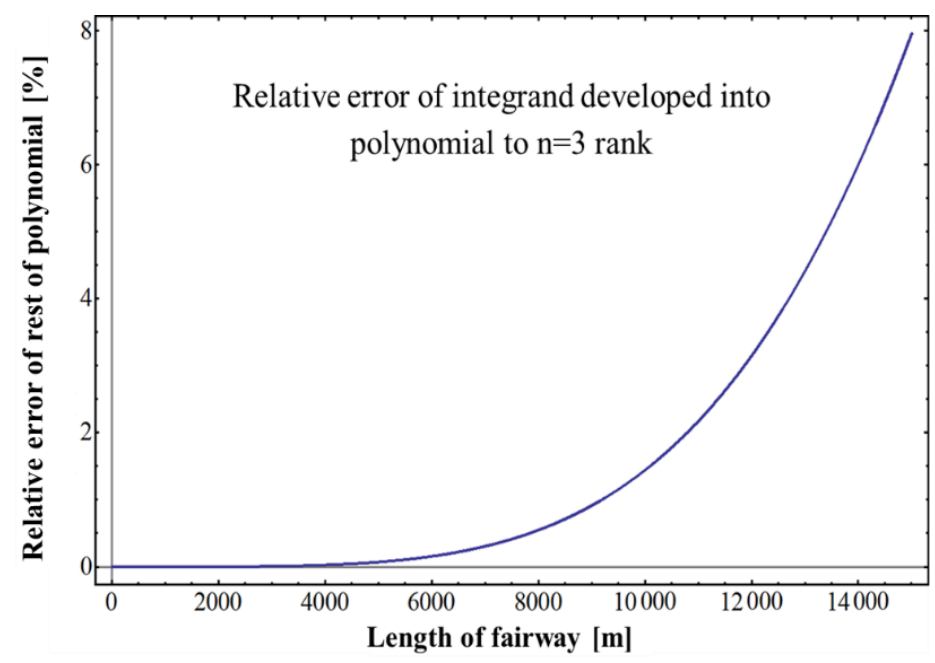

Fig. 5. Relative error of integrand developed into polynomial to $n=3 \mathrm{rank}$

Development of the integrand into the polynomial to $n=8$ rank is presented in Figures 6, 7 and 8.

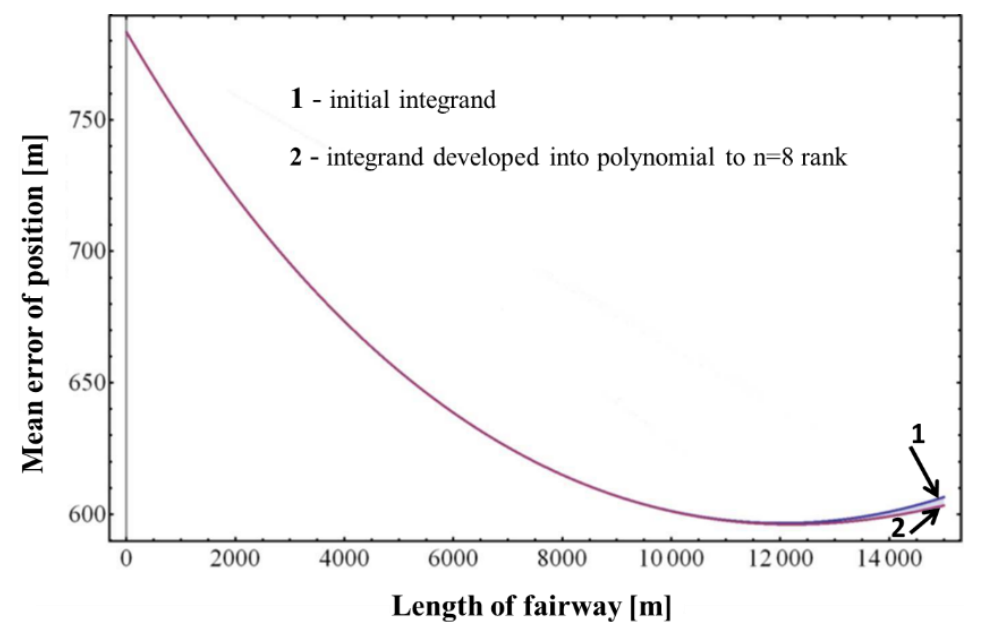

Fig. 6. Graphical interpretation of integrand without development into polynomial and of integrand developed into polynomial to $n=8 \mathrm{rank}$

The Table 1 and above drawings do show that values of the absolute errors and relative errors of the integrand developed into the polynomial to $n=3$ rank are not acceptable in a situation when the watercraft has already proceeded $4000 \mathrm{~m}$ of the minesweeping path. This is the moment when the value of the absolute 
error starts growing radically, obtaining the maximal value equal $2717 \mathrm{~m}$. Development of the integrand into the polynomial to $n=8$ rank considerably improved indexes describing the gap between the functions under discussion.

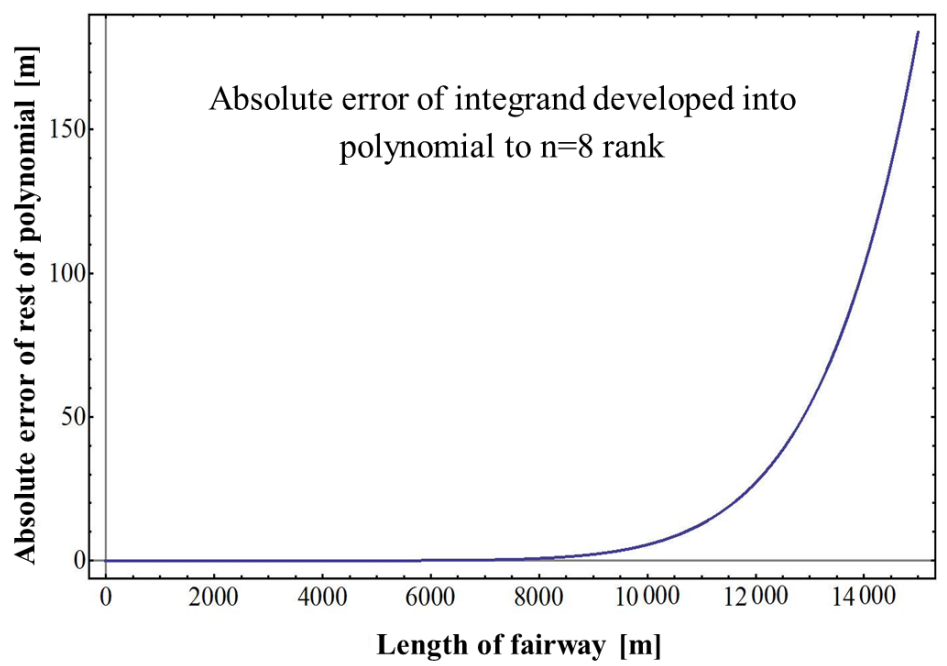

Fig. 7. Absolute error of integrand developed into polynomial to $n=8$ rank

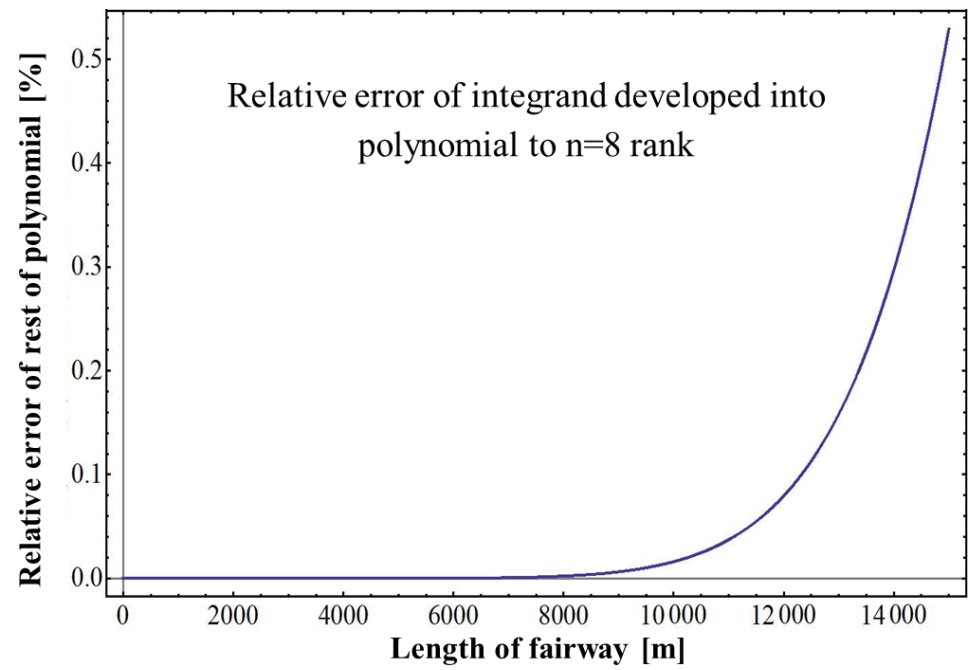

Fig. 8. Relative error of integrand developed into polynomial to $n=8 \mathrm{rank}$

As a final effect, only the integrand developed to the polynomial as far as to the $n=13$ rank allowed to obtain the optimal integrand polynomial after 
the $x_{S}$ variable. Based on Figure 9, one may observe that two graphs of the functions under discussion overlap.

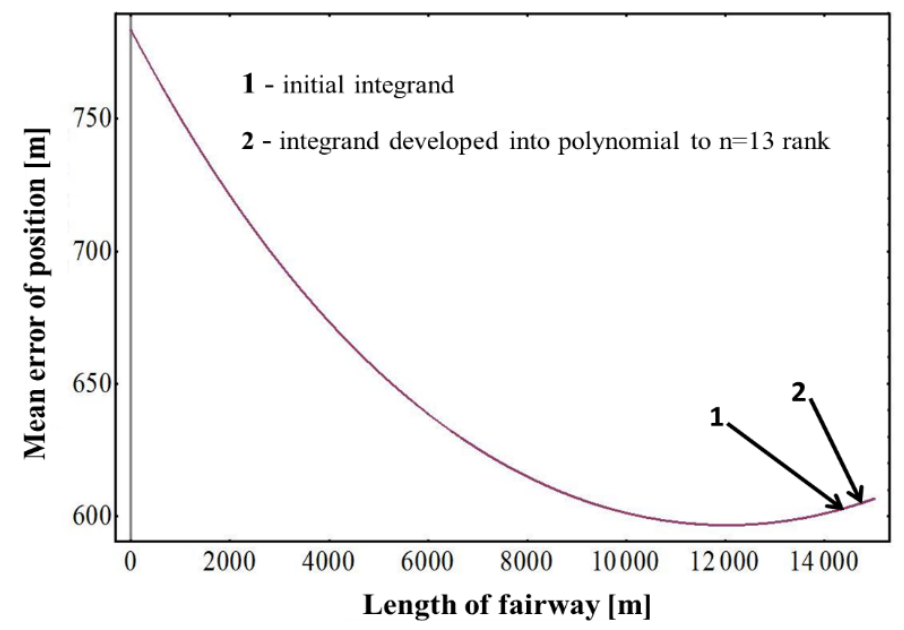

Fig. 9. Graphical interpretation of integrand without development into polynomial and of integrand developed into polynomial to $n=13 \mathrm{rank}$

Figures 10 and 11 are illustrating a graphical interpretation of the absolute errors and relative errors of the integrand developed into the polynomial to $n=13$ rank; according to the Table 1, values of these errors become minimal for such a function.

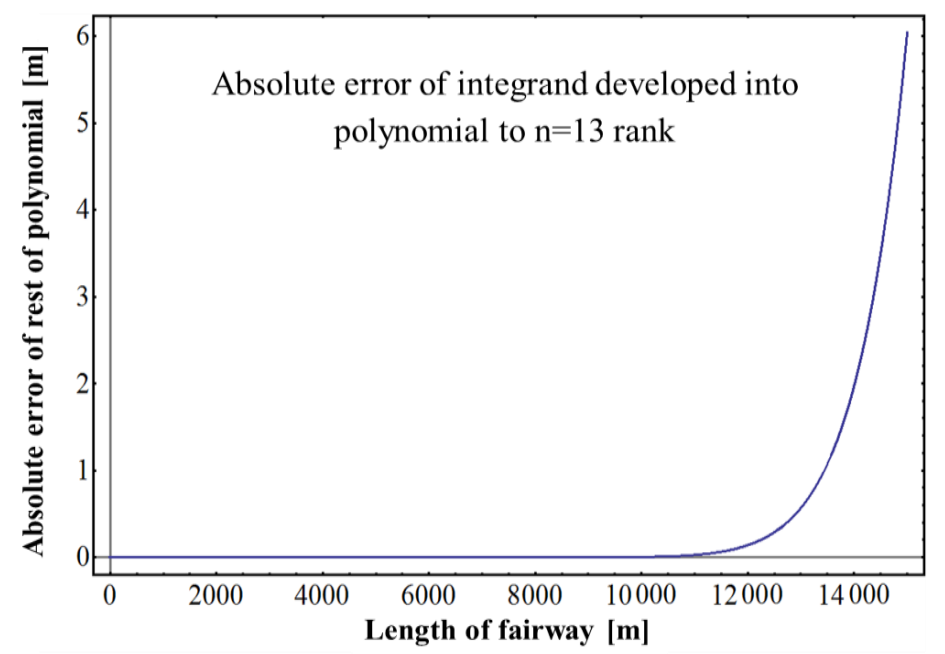

Fig. 10. Absolute error of integrand developed into polynomial to $n=13$ rank 


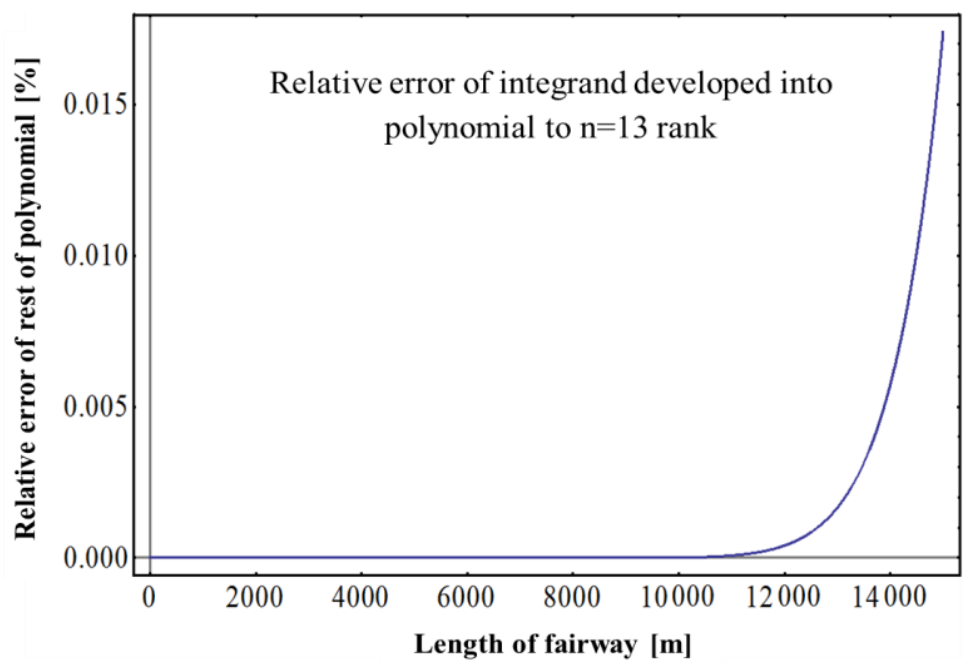

Fig. 11. Relative error of integrand developed into polynomial to $n=13$ rank

Optimum values $l_{Z}$ and respective values of fields' surfaces under the function decomposition (9) are calculated in the second part of this paper. Obtained results are presented in Table 2.

Tab. 2. Optimum values $l_{Z}$ and respective values of fields' surfaces under decomposition of function $P_{M_{2 N R}}$ developed into polynomials for particular n ranks of development

\begin{tabular}{|c|c|c|}
\hline \multirow{2}{*}{$\begin{array}{l}\text { Value of n rank of developed } \\
\text { polynomial after } x_{S} \text { variable }\end{array}$} & $\begin{array}{c}\text { Optimum values } \\
l_{Z}\end{array}$ & $P_{M_{2 N R}}$ \\
\cline { 2 - 3 } & {$[\mathrm{m}]$} & {$\left[\mathrm{m}^{2}\right]$} \\
\hline$n=1$ & 21795.49 & 7718662.79 \\
\hline$n=2$ & 23823.43 & 10210166.38 \\
\hline$n=3$ & 23708.01 & 9528642.93 \\
\hline$n=4$ & 24075.20 & 9615310.97 \\
\hline$n=5$ & 24069.28 & 9677376.45 \\
\hline$n=6$ & 24030.84 & 9678240.12 \\
\hline$n=7$ & 24042.97 & 9662137.01 \\
\hline$n=8$ & 24061.26 & 9660756.49 \\
\hline$n=9$ & 24061.00 & 9666724.90 \\
\hline$n=10$ & 24054.82 & 9667829.84 \\
\hline$n=11$ & 24053.88 & 9665553.09 \\
\hline$n=12$ & 24055.55 & 9664961.74 \\
\hline$n=13$ & $\mathbf{2 4 0 5 5 . 7 4}$ & 9665883.96 \\
\hline$n=14$ & 24055.09 & 9666161.24 \\
\hline
\end{tabular}


From the analysis of Table 2, it results that the process of development of the integrand into the polynomial could be, in this case, stopped on the $n=8$ rank of the development; this would provide an optimized $l_{Z}$ value equal $24061.26 \mathrm{~m}$. This value differs from the optimum value (for the $n=13$ rank) by $5.5 \mathrm{~m}$. The navigator shall obtain the most favourable accuracies in an identification of the observed positions under discussion when the distance between the beacons $Z, 2$ and Z,1 varies within the range from 24030 to $24075 \mathrm{~m}$.

\section{CONCLUSIONS}

1. In the age of computer power progress, application of integral calculus, as well as surveying calculations and data adjustments and related numerical methods, seem to be the right direction in the development of research on the optimum identification of navigational signs' positions quickly and explicitly.

2. The presented in the paper method of searching the optimal $n$ rank of the development of the integrand into the polynomial enables to identify the optimum $l_{Z}$ distance between the beacons $Z, 1$ and $Z, 2$.

3. It should be borne in mind that - in case of change of the minesweeping path axis parameters (the length of the path a $x_{S}^{k}$ nd the distance between the path and the baseline $-l_{S}$ ), the absolute and the relative error should be each time calculated, in order to identify the optimal $\mathrm{n}$ rank of the integrand development into the demanded polynomial.

\section{REFERENCES}

[1] Czaplewski K., The optimization of the set-up of the quotient navigational system in relation to the mean error of the position with the simplex method [in Polish], 'Zeszyty Naukowe AMW', 1998, No. 2, pp. 5-14.

[2] Czaplewski K., The optimization of the navigational system based on the quotient of the distances [in Polish], Doctoral thesis, Polish Naval Academy, Gdynia 1999.

[3] Czaplewski K., Positioning with Interactive Navigational Structures Implementation, 'Annual of Navigation', 2004, No. 7.

[4] Felski A., Specht C., Some aspects of the optimization in the utilization of DGPS on South Baltic, 'Zeszyty Naukowe AMW', 1995, No. 3, pp. 21-29. 
[5] Fortuna Z., Macukow B., Wąsowski J., Numerical methods [in Polish], WNT, Warszawa 1993.

[6] Gołąb S., The outline of higher mathematics [in Polish], Czytelnik, Warszawa 1948.

[7] Górski S., Jackowski K., Urbański J., Estimation of the accuracy of the navigation [in Polish], WSM, Gdynia 1990.

[8] Kołaczyński S., Methodical and accuracy aspects of using the quotient of the distance as the navigational parameter to positioning [in Polish], ART Publishers, Olsztyn 1978.

[9] Kołaczyński S., The expository content of results of inspected measurements of the depth [in Polish], 'Zeszyty Naukowe AMW', 2013, No. 2, pp. 49-56.

[10] Kopacz Z., Morgaś W., Urbański J., Evaluation of the accuracy of the position of the ship [in Polish], Polish Naval Academy, Gdynia 2007.

[11] Narloch A., The settlement of the position of the navigational sign erection in the digraph structure [in Polish], 'Logistyka', 2014, No. 6, pp. 974-979.

[12] Naus K., The influence of fatal errors on the accuracy of the ship's position by means of the method of the extended Kalman filter and the geodesic resistant settlement [in Polish], 'Logistyka', 2014, No. 3, CD 1.

[13] Naus K., Narloch A., The distribution of the accuracy of coordinate appointive with terrestrial methods in relation to two and three navigational signs [in Polish], 'Logistyka', 2014, No. 3, CD 1.

[14] Naus K., Wąż M., Accuracy in fixing ship's positions by camera survey of bearings, 'Geodesy and Cartography', 2016, Vol. 60, No 1, pp. 61-73.

[15] Wiśniewski Z., Methods of the elaborations of measurements results in the navigation and the hydrography [in Polish], Polish Naval Academy, Gdynia 2004.

[16] Wiśniewski Z., The algebra of the matrix. Probabilistic and statistical bases of the adjustment theory [in Polish], ART Publishers, Olsztyn 1999.

Received November 2016

Reviewed May 2017

Published 26.09.2017

\section{ARKADIUSZ NARLOCH}

Polish Naval Academy

Śmidowicza 69 Str., 81-127 Gdynia, Poland

e-mail: a.narloch@amw.gdynia.pl

\section{STANISŁAW KOLACZYŃSKI}

Polish Naval Academy

Śmidowicza 69 Str., 81-127 Gdynia, Poland

e-mail: s.kolaczynski@amw.gdynia.pl 


\section{STRESZCZENIE}

W artykule podjęto próbę ustalenia wpływu rozwijanego wielomianu na dokładność wyznaczenia współrzędnych pozycji z pomiaru dwóch namiarów. Analizie poddano strukturę nawigacyjną składającą się z dwóch znaków nawigacyjnych, względem których jednostka manewrująca na zadanym obszarze wyznaczała swoją pozycję. W następstwie tego wyliczono liczbowe wskaźniki dokładnościowe. Dały one podstawę do wyprowadzenia wniosków na temat wpływu odległości między znakami na dokładność wyznaczania współrzędnych pozycji. 